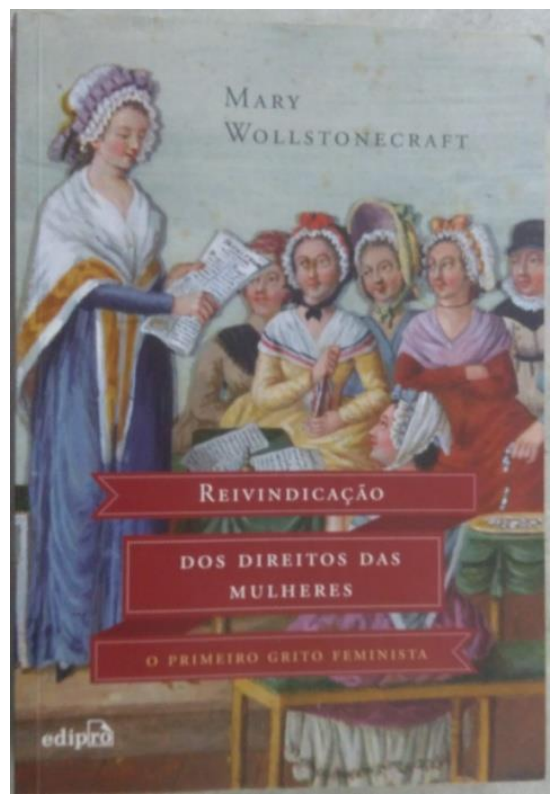

RESENHA: WOLLSTONECRAFT, Mary. "Reivindicação dos direitos das mulheres". Tradução e notas de Andreia Reis do Carmo. São Paulo: Edipro/Boitempo, 2015, 272p [ISBN 978-85-7283-927-3].

\title{
Mary Wollstonecraft e os direitos das mulheres
}

\author{
JAIME FARHERR ${ }^{1}$
}

A Resenha se foca no recente livro Reivindicação dos direitos das mulheres de Mary Wollstonecraft (1759-1797) publicado no Brasil, em 2015, pela editora Edipro e pela Boitempo. A partir desse trabalho, viso apresentar algumas contribuições da filósofa inglesa para a reivindicação de direitos das mulheres e, vinculado a isso, algumas contribuições quanto à ética numa perspectiva feminina. Wollstonecraft é uma precursora do feminismo. Com base em alguns dos autores que tratam sobre ela em, em particular, em seu texto, apresentarei alguns temas tratados na obra sem a pretensão de esgotar o assunto, mas apenas para estimular a leitura da mesma e mostrar a sua importância.

Mary Wollstonecraft nasceu em Londres, em uma família de classe média, que perdeu seu "status" social devido aos desmandos do pai. Mary teve que transpor vários obstáculos já na infância e na adolescência, devido à crueldade de seu pai, à

\footnotetext{
${ }^{1}$ Professor de Filosofia e História da rede estadual do Paraná. Graduado em Filosofia pela UNIOESTE, tendo participado do PET/Filosofia entre abril de 1994 e janeiro de 1997. Concluiu em 2017 o Programa de Desenvolvimento Educacional - PDE da SEED/PR, com o tema de pesquisa "As mulheres na filosofia, o feminismo e a ética", com a orientação da Professora Dra Ester Maria Dreher Heuser. E-mail: jaime_farherr@hotmail.com.
} 
fraqueza e parcialidade da mãe (que preferia o filho mais velho) e ao modo como ela própria, Mary, defendia a mãe dos maus tratos do pai. Segundo Miranda (2015), a filósofa inglesa teve uma filha chamada Fanny em 1794, com Gilbert Imlay, um comerciante americano. Em 1796 separou-se de Imlay e no ano seguinte casou-se com William Godwin. Em agosto de 1797 nasceu outra filha, Mary Wollstonecraft Godwin, futura esposa de Shelley e autora de Frankestein. A filósofa morreu em 1797, por causa de complicações relacionadas ao parto.

Maria Luísa Ribeiro Ferreira afirma na obra As mulheres na filosofia (2009) que a originalidade de Mary Wollstonecraft está no caminho que traçou para si e nas perspectivas que abriu à condição feminina da época. Recusou paternalismos, se impôs pelo trabalho e pela pesquisa intelectual. Lutou por uma causa, com base nas vivências e no estudo. Ela não se integrou à visão de mundo da época. Escreveu textos variados em sua curta vida de 38 anos: romances, cartas, relatos de viagens, ensaios, tratados de pedagogia, etc.

A obra Reivindicação dos Direitos das Mulheres foi publicada em 1792 e recebeu influência da revolução francesa. De acordo com Luis Felipe Miguel (2014), a imensa maioria dos revolucionários franceses não tinha interesse ou era hostil aos direitos da mulher. Eles seguiam os passos do filósofo Rousseau, "maior inspiração filosófica para a Revolução" (MIGUEL, 2014, p. 20). Mas em meio à revolução francesa, as mulheres apresentaram suas reivindicações, cujo documento mais importante foi a "Declaração dos Direitos da Mulher e da Cidadã", escrita por Olympe de Gouges. ${ }^{2}$ Apesar dos enormes méritos de Olympe de Gouges, o seu esforço, segundo Miguel, não chegou à compreensão das raízes da opressão das mulheres. Esse resultado foi obtido pela filósofa Mary Wollstonecraft. Foi a promessa de emancipação dos homens feita na revolução francesa que levou Wollstonecraft a sistematizar seu estudo sobre a necessidade de emancipar as mulheres e os obstáculos que deveriam ser enfrentados. Ela foi uma das principais representantes do chamado feminismo liberal, surgido no século XVIII e desenvolvido no século XIX.

A obra Reivindicação dos Direitos das Mulheres divide-se em 13 capítulos, tratando de vários temas, a começar pela necessidade de provar que as mulheres são racionais, pois "o século XVIII ainda discutia sobre a existência da racionalidade nas mulheres, excluindo-as da vida pública." (MIRANDA, 2015, p. 14). Mary Wollstonecraft investiga, entre outras coisas, as causas da degradação das mulheres, trata do casamento, da modéstia, da moralidade, do dever dos pais, da educação nacional, etc. Ela também defende que as mulheres tenham representantes no

\footnotetext{
${ }^{2}$ Olympe de Gouges foi guilhotinada em 1793, por ter se oposto aos revolucionários Robespierre e Marat, "que a consideravam mulher 'desnaturada' e 'perigosa demais'" (ASSMANN, 2007, p.1). Na sentença de condenação, ela foi acusada "de ter querido ser um homem de Estado e ter esquecido as virtudes próprias a seu sexo." (ALVES; PITANGUY, 2003, p. 34). Aparentemente Wollstonecraft não conheceu Olympe de Gouges, apesar de ter morado na França entre dezembro de 1792 e abril de 1795 para observar e registrar a revolução.
} 
Parlamento, numa época que sequer as mulheres tinham direito ao voto. $\mathrm{Na}$ introdução da obra Mary afirma que sua atenção maior se volta às mulheres de classe média.

Mary Wollstonecraft enfrentou vários escritores machistas de sua época. Um deles foi o filósofo Rousseau. Para Ferreira (2009), Rousseau escreve ensaios onde a mulher tem um papel importante, mas ele também é responsável por representar a mulher de modo inferior, principalmente em sua obra Emílio, na qual afirma, por exemplo, que a mulher deveria ser educada para agradar o homem, ser útil a ele e cuidar dos filhos. Para Mary Wollstonecraft, o modelo de mulher defendido por Rousseau é uma mulher fraca e submissa, sem personalidade. Parece ser bem atual essa crítica, especialmente àqueles que defendem uma mulher "bela, recatada e do lar". Um dos pontos centrais das teses de Wollstonecraft é a ênfase em que a mulher exercite o seu entendimento, exercite a razão. A filósofa afirma:

Contudo, Rousseau e a maioria dos escritores masculinos que seguiram seus passos, calorosamente inculcaram que toda a tendência da educação feminina deve ser direcionada para um ponto: torná-las agradáveis. [...] Para ganhar os afetos de um homem virtuoso, o fingimento é necessário? A natureza deu a mulher uma estrutura física mais fraca que a do homem; [...] A fraqueza pode estimular a ternura, e gratificar o orgulho arrogante do homem, mas os afagos insolentes de um protetor não gratificarão uma mente nobre que pede e deseja ser respeitada. [...] Além disso, a mulher que fortalece seu corpo e exercita sua mente irá, ao administrar sua família e praticar várias virtudes, tornar-se uma amiga, e não a dependente humilde de seu marido (WOLLSTONECRAFT, 2015, p. 52 e 54).

De acordo com Ferreira (2009), a filósofa do século XVIII foi a primeira a distinguir sexo e gênero, embora não use esses conceitos, pois preparou o terreno para a separação entre o biológico e o cultural. Um exemplo disso pode ser visto nos seguintes trechos da obra:

Quanto às observações de Rousseau, as quais desde então tem sido ecoadas por vários escritores, de que elas naturalmente têm, provenientes de seus nascimentos, independente da educação, um carinho pelas bonecas, vestimentas e conversas - elas são tão pueris a ponto de não merecerem uma refutação séria. [...] Meninas e meninos, resumidamente, brincariam inofensivamente juntos, se a distinção do sexo não fosse inculcada muito antes da natureza fazer qualquer diferenciação. (WOLLSTONECRAFT, 2015, p. 69-71).

Segundo Ferreira (2009), o “Ouse saber!" que Kant dirigiu à humanidade é direcionado por Mary Wollstonecraft às mulheres. A época do Iluminismo em que ela viveu é sensível aos direitos dos homens, mas as mulheres não estão automaticamente incluídas. Daí a necessidade de retirar a mulher da menoridade, 
elevando-a a um ser humano completo; isso exige aprendizagem paciente, esforço, uma educação com objetivos definidos e que combata os preconceitos.

Como foi dito no início, Wollstonecraft é uma precursora do feminismo. Ela afirma que uma das causas principais da mulher não estar numa condição de igualdade em relação ao homem, é que ela é educada através de vários meios a exercer apenas a sua sensibilidade, em outras palavras, a sua delicadeza. A mulher fica presa aos seus sentidos, o que produz um rebaixamento moral. Para ter igualdade entre os sexos, ela precisa ser educada para exercitar a razão, que é o único fundamento para o caráter independente. "Para se tornar respeitável, o exercício do entendimento é necessário, não há outro fundamento para a independência de caráter; eu quero explicitamente dizer que elas devem apenas se curvar para a autoridade da razão" (WOLLSTONECRAFT, 2015, p. 81).

Ferreira (2009) destaca que as mulheres não ficam isentas das críticas de Wollstonecraft. Ela atribui às mulheres alguma responsabilidade pela propagação de teses que inferiorizam a mulher. Critica a superficialidade das mulheres, a futilidade, etc. Esses defeitos não têm nada de natural, mas surgem de uma educação deficiente. Percebemos novamente a distinção entre sexo e gênero. Wollstonecraft afirma no capítulo VI de sua obra que há ideias incutidas de forma prematura e que prejudicam o caráter, sobretudo das mulheres. Desde meninas elas são sensualizadas com falsas noções de beleza e delicadeza, que raramente podem ser desfeitas pela razão. Na vida adulta elas vão buscar apenas excitar emoções nos homens. Elas são feitas mulheres na infância e infantilizadas na vida adulta. A educação das mulheres as torna objeto de desejo. Nas palavras de Wollstonecraft:

Contudo, fêmeas, que são feitas mulheres ainda quando são meras crianças, e trazidas de volta à infância quando deveriam deixar o andador para sempre, não têm força de mente suficiente para apagar as superinduções da arte que amaciaram a natureza. [...] Esta cruel associação de ideias, à qual cada coisa conspira para desviar todos os seus hábitos de pensar ou para falar com mais precisão dos sentimentos, recebe novas forças quando [elas] começam a agir um pouco por si mesmas; pois elas, então, percebem que é somente por meio de excitar emoções nos homens, que o prazer e o poder são obtidos. (WOLLSTONECRAFT, 2015, p. 169).

Como se coloca o tema da ética na obra Reivindicação dos Direitos das Mulheres? Há uma ética feminina nessa perspectiva da autora? No feminismo há muitas contribuições e debates quanto ao tema da ética. Segundo Ferreira (2009) os diferentes feminismos ${ }^{3}$ contribuem na discussão sobre universalidade dos valores morais e na existência ou não de uma ética feminina. Ferreira vê com bons olhos os estudos que apontam para a existência de uma moral feminina, como os da psicóloga estadunidense Carol Gilligan. No Brasil, uma das autoras que defende uma

\footnotetext{
3 Ferreira chama de movimentos feministas, devido às várias tendências aí presentes.
} 
ética feminina é a filósofa Maria da Penha F. S. de Carvalho (2006). Uma ética do ponto de vista feminino não é exclusivamente o ponto de vista da mulher. $\mathrm{O}$ "feminino" é entendido por Carvalho como um termo abrangente que designa sentimentos de cuidado, simpatia, compaixão, experiências de solidariedade, afetos, etc, que são culturalmente associados à mulher.

Pois bem, quais as contribuições da obra de Wollstonecraft quanto às questões levantadas acima? A reivindicação da filósofa pela igualdade entre homens e mulheres expressa uma ética, pois significa a defesa da libertação da mulher em relação à opressão. Também há a defesa de virtudes, principalmente a modéstia, a qual se diferencia da humildade e da vaidade, que não são virtudes. "A modéstia, neste último significado do termo, é aquela sobriedade da mente que ensina o homem a não pensar mais do que deveria de si mesmo, e deve ser distinguido da humildade, porque humildade é um tipo de autodegradação" (WOLLSTONECRAFT, 2015, p. 175). Homens e mulheres precisam cultivar a modéstia, mas para as mulheres isso é mais difícil, porque elas precisam buscar o conhecimento ao qual não foram estimuladas e reduzir o exercício da sensibilidade, ao qual foram estimuladas em excesso. Há uma relação entre igualdade, moralidade e virtude:

Deve haver mais igualdade na sociedade, ou a moralidade nunca irá ganhar terreno, e esta igualdade virtuosa não irá descansar firmemente, mesmo se fundada em uma rocha, se metade da humanidade for acorrentada ao fundo, pelo destino, pois isto irá continuamente miná-la pela ignorância ou orgulho. É em vão esperar virtude das mulheres até que elas sejam, em algum grau, independente dos homens, mais ainda, é em vão esperar a força da afeição natural, que poderia fazer delas boas esposas e mães. (WOLLSTONECRAFT, 2015, p. 202).

A ética feminina está presente na ênfase de Wollstonecraft para que a mulher exercite seu entendimento, saia da condição de menoridade e alcance a igualdade. Ferreira (2009) afirma que Wollstonecraft também é precursora quanto à ética feminina do cuidado, ao destacar funções de mãe e educadora. "A maternidade torna-se um verdadeiro cartão de cidadania. É por ela que a condição feminina adquire um justo prestígio" (FERREIRA, 2009, p. 147). De fato, Wollstonecraft defende que as mulheres têm pleno direito às mais variadas profissões, mas afirma que o cuidado das crianças é um dever natural das mulheres e que para ser uma boa mãe é preciso ter um grande desenvolvimento intelectual. $\mathrm{O}$ papel das mães é fundamental, principalmente nos primeiros anos de vida das crianças, quando o caráter é formado. Os cuidados com a saúde da família também são atribuições da mulher. Mas tudo isso só é possível de ser efetivado se houver igualdade entre os sexos. Essa ideia do cuidado como um dever da mulher pode ser interpretada hoje como um resquício de machismo, como legitimação da dupla jornada, etc. Mas até nesse aspecto Mary esteve à frente de seu tempo, pois essas afirmações estão 
fundadas na necessidade de autonomia feminina, de reconhecimento social da maternidade e da mesma educação para homens e mulheres.

Essas e outras ideias presentes na obra Reivindicação dos Direitos das Mulheres colocam Wollstonecraft como uma precursora do feminismo, como firme defensora da autonomia das mulheres e de sua participação política, como questionadora de autores que inferiorizaram as mulheres. Também a colocam como precursora da distinção entre sexo e gênero, tema que precisa ser debatido ainda hoje, ao contrário do que dizem os defensores da censura às escolas. As questões éticas presentes na obra, particularmente de uma ética feminina, também são contribuições importantes da filósofa. Várias questões levantadas pela filósofa antecipam discussões contemporâneas no campo do feminismo filosófico, da teoria política e outras áreas. Tudo isso coloca Mary Wollstonecraft ao mesmo nível de filósofos considerados clássicos do século XVIII e justificam o estudo desta filósofa.

\section{Referências:}

ALVES, B. M; PITANGUY, J. O que é feminismo. 8. ed. São Paulo: Brasiliense, 2003.

ASSMANN, S. J. Apresentação à "Declaração dos Direitos da Mulher e da Cidadã".

INTERthesis: Revista Internacional Interdisciplinar, v. 4. no 1, Florianópolis, jan./jun. 2007.

Disponível em: <https://dialnet.unirioja.es/servlet/articulo?codigo=5175681>. Acesso em: 28 nov. 2016.

CARVALHO, M. P. F. dos Santos de. Ética e gênero: a construção de uma sociedade mais feminina. Kalagatos - Revista de Filosofia do Mestrado Acadêmico em Filosofia da UECE, Fortaleza, v. 3, n. 6, p. 67 a 89, verão de 2006.

FERREIRA, M. L. R. As mulheres na filosofia. Lisboa: Edições Colibri, 2009.

MIGUEL, L. F. O feminismo e a política. In.: In.: MIGUEL, Luis Felipe; BIROLI, Flávia. Feminismo e política: uma introdução. São Paulo: Boitempo, 2014, p. 17 a 29.

MIRANDA, D. M. Apresentação da obra Reivindicação dos direitos das mulheres. In.: WOLLSTONECRAFT, Mary. Reivindicação dos direitos das mulheres. Tradução e notas de Andreia Reis do Carmo. São Paulo: EDIPRO, 2015.

WOLLSTONECRAFT, M. Reivindicação dos direitos das mulheres. Tradução e notas de Andreia Reis do Carmo. São Paulo: EDIPRO, 2015.

Submissão: 15. 12. 2017 / Aceite: 20. 12. 2017 